\title{
Fora da Capital \\ - Oficina de documentários em vídeo digital
}

Fora da Capital - Taller de

documentales en video digital

Lucas Rossi Gervilla

1 Doutorando (Bolsa Capes) e mestre em Artes Visuais no Instituto de Artes da UNESP; bacharel em Comunicação e Multimeios pela PUC-SP. Participou de mais de 160 produções audiovisuais. Em 2020, dirigiu seu primeiro longa-metragem, intitulado Ruinoso.

Currículo Lattes: http://lattes.cnpq.br/4985531457212451

Orcid: https://orcid.org/0000-0002-4423-0137

Email: lucas.gervilla@unesp.br 


\section{Resumo}

Documentários sempre estiveram no centro das discussões cinematográficas, seja pelas suas semelhanças e/ou diferenças com a ficção, pela sua liberdade estética ou vanguardismo. Atualmente, a tecnologia digital permite que documentários sejam produzidos e distribuídos em curtíssimos intervalos de tempo. Esses fatores têm gerado um número crescente de interessados na produção documental. A partir desse ponto, foi criada, pelo próprio autor, a oficina Documentários em Vídeo Digital, cujo o principal objetivo é compartilhar com os participantes ferramentas para que esses possam contar suas próprias histórias. $\bigcirc$ artigo trata dos processos de criação, metodologia e desenvolvimento da atividade em mais de 40 cidades do estado de São Paulo; e o processo de realização do documentário longa-metragem Fora da Capital, resultante das oficinas. Também é apresentada uma breve retrospectiva histórica do documentário, a constante de evolução de sua linguagem e seus atuais desdobramentos.

\section{Palavras-chave}

audiovisual; documentário; oficina; vídeo digital.

\section{Resumen}

Los documentales siempre han estado en el centro de las discusiones cinematográficas, sea por sus similitudes y/o diferencias con la ficción, libertad estética o vanguardia. Actualmente, la tecnología digital permite que los documentales sean hechos y distribuidos en intervalos de tiempo muy cortos. Estos factores han generado un número creciente de personas interesadas en la producción de documentales. De este interés, el propio autor creó el taller Documentales en Video Digital, cuyo objetivo principal es compartir con los participantes herramientas para que ellos puedan contar sus propias historias. El artículo trata sobre los procesos de creación, metodología y desarrollo de la actividad en más de 40 ciudades del estado de São Paulo; y aborda el proceso de realización del documental largometraje Fora da Capital, resultante de los talleres. También se presenta una breve retrospectiva histórica acerca de los documentales, el constante proceso de evolución de su lenguaje y sus desarrollos actuales.

\section{Palabras-clave}

audiovisual; documentales; taller; video digital. 


\section{Introdução}

Entre 2013 e 2014, escrevi o texto "Câmeras DSLR1 e Documentários", para compartilhar minhas experiências com o uso desse tipo de câmera no cinema documental. Desde que as primeiras DSLR com capacidade de filmagem no formato Full HD chegaram ao mercado - em meados de 2008 - iniciou-se uma reviravolta na produção audiovisual; pois tornou-se possível obter no vídeo uma qualidade de imagem só antes vista em modelos caríssimos, acessíveis apenas à grandes produções. O texto menciona os processos de trabalho dos meus curtas-metragens Abrasivo (2013), Labmovel (2012), Música Operária (2014) e a série de intervenções Abandomento (2013) ${ }^{2}$.

De 2016 a 2017, trabalhei como professor no curso Produção de Áudio e Vídeo da ETEC Jornalista Roberto Marinho ${ }^{3}$. Durante esse período, percebi quais eram as dúvidas mais frequentes entre os estudantes na hora de filmar e quais conteúdos teóricos sentiam falta.

Após o trabalho na ETEC, fiz algumas reflexões baseadas nas aulas, dúvidas levantadas pelos alunos e críticas em relação ao texto de 2014. Como resultado, adaptei o conteúdo didático para o formato de oficina e a chamei de Documentários em Vídeo Digital. No início de 2018, a atividade foi integrada aos programas Pontos MIS e Oficinas Culturais da POIESIS. Nos dois anos seguintes, tive a oportunidade de viajar por 45 cidades de São Paulo, ministrando o curso para públicos diversos.

Esse artigo compartilha experiências de aprendizado vivenciadas na estrada; e também o processo de montagem de filme Fora da Capital ${ }^{4}$, resultado dos encontros proporcionados pela oficina e do trabalho coletivo de mais de 500 participantes. Também são feitos apontamentos acerca da pertinência do documentário nos dias atuais, 125 anos depois do surgimento do cinema.

\section{Filme ou documentário?}

"E hoje, a batalha de ideias que acontece na tela do mundo pertence ao cinema documentário, que tem um papel muito especial."

V. Ivanov, 1983.

"O cinema nasceu como documentário", uma afirmação tão frágil quanto as definições que tentam diferenciá-lo da ficção. Considera-se o marco inicial do cinema os primeiros filmes dos irmãos franceses Auguste e Louis Lumière, exibidos

\footnotetext{
1 DSLR é a sigla em inglês para Digital Single-Lens Reflex. Uma câmera digital que combina o sistema óptico de um modelo SLR a um sensor digital de imagem.

2 Todos disponíveis no Vimeo.

3 ETEC - Escola Técnica Estadual de São Paulo.

${ }^{4}$ Disponível em: <https://youtu.be/A2KAxJgxn1k>.
} 
publicamente pela primeira vez em dezembro de 1895. Há controvérsias sobre esse pioneirismo, pois os irmãos alemães Emil e Max Skladanowsky realizaram uma exibição pública de imagens em movimento - captadas com o seu bioscópio - quase dois meses antes. Talvez, por Paris ser uma cidade mais glamurosa do que Berlim, o crédito ficou com os franceses. De uma forma ou de outra, o cinema nasceu como um trabalho em equipe. Então, se tomarmos Auguste e Louis como os inventores do cinema, A Chegada do Trem à Estação e A Saída dos Operários da Fábrica são os dois primeiros filmes da história. Ambos, além de trazerem suas sinopses no próprio título, apresentam estruturas parecidas, onde a câmera (cinematógrafo) estática observa o desenvolvimento de uma situação cotidiana. Os dois também têm curta duração, menos de um minuto. Evidentemente, isso se deve às limitações tecnológicas da época, mas também poderia ser um prenúncio da duração dos vídeos no Instagram e Tik Tok.

É justamente por mostrarem situações cotidianas que surgiu a afirmação que abre a atual seção desse artigo, mas pouco se questiona sobre espontaneidade dessas situações. Em A Saída dos Operários da Fábrica, a fábrica em questão era da família dos diretores ${ }^{5}$. Assistindo ao filme com um olhar atento pode-se notar que, entre dezenas de trabalhadores, nenhum deles olha para a câmera. Parece improvável que ninguém teve a curiosidade de olhar para um dispositivo, até então, desconhecido. Além disso, existe uma cadência no ritmo da saída: primeiro, saem apenas mulheres, em seguida, surgem os primeiros homens, depois, algumas bicicletas e, por fim, uma carruagem, dando um final apoteótico ao filme. É plausível que ali tenha acorrido uma das primeiras direções cinematográficas da história. Se levarmos em conta que Auguste e Louis eram patrões dos operários, o filme fica ainda menos romântico.

O mesmo pode ser observado em A Chegada do Trem à Estação. Em uma plataforma movimentada ninguém olha para a câmera, nem mesmo o fiscal da estação.

Se as pessoas retratadas nos filmes dos Lumière foram ou não dirigidas, isso não reduz a importância dessas obras, mas transforma a afirmação em pergunta: "o cinema nasceu como documentário?".

Não demorou muito para iniciar-se a popularização do cinema, pois os Lumière

eram negociantes experientes, que souberam tornar seu invento conhecido no mundo todo e fazer do cinema uma atividade lucrativa, vendendo câmeras e filmes. (COSTA, 2006, p. 19)

Meses depois, Alice Guy-Blaché dirigiu A Fada do Repolho (1896), a primeira ficção cinematográfica roteirizada. Logo em seguida, "o cinema de ficção sequestrou o documentário ainda em seu berço, graças à fascinação que todos sentimos pela fantasia de Georges Méliès"6. (RUFFINELLI, 2017, p. 11).

\footnotetext{
${ }^{5} \mathrm{Na}$ época, a família Lumière era a maior produtora de placas fotográficas da Europa, o que também contribuiu para a invenção do cinematógrafo.

6 Ilusionista e cineasta francês. Diretor do célebre filme Viagem à Lua (1902). Produziu dezenas de
} 
Na década de 1930, o diretor e produtor escocês John Grierson criou o termo documentário e o definiu como "o tratamento criativo da realidade" (1936 apud LABAKI, 2006, p.37). Mas já era tarde demais e

o documentário [...] pareceu estabelecer-se como um epifenômeno da reportagem, da notícia e, em grande medida, nas mãos dos antropólogos. A questão era conhecer o outro, as culturas diferentes, que não tinham alcançado a modernidade. (RUFFINELLI, 2017, p. 11)

Isso não impediu que o gênero fosse aparelhado como instrumento de propaganda por vários governos. Nessa linha incluem-se: $O$ Triunfo da Vontade (Alemanha, 1935), de Leni Rifenstahl; a série Why We Fight (EUA, 1942-1945), de Frank Capra; A Sexta Parte do Mundo (URSS, 1926), de Dziga Vertov; além dos filmes produzidos entre as décadas de 1920 e 1930 pela empresa estatal britância Empire Marketing Board, da qual Grierson fez parte. Assim, se esqueceu que "o filme documentário [...] é cinema antes de tudo" (RAMOS, 2016, p. 14) e esse foi colocado em segundo plano.

O panorama só começou a mudar na virada da década de 1950 para 1960, no período

quando Glauber Rocha proclamou a necessidade de "uma câmera na mão e uma ideia na cabeça", esse programa coincidiu com [...] a revolução tecnológica [...] a partir desse momento, foi possível usar câmeras leves e a simultaneidade de som e imagem. (RUFFINELLI, 2017, p. 12)

É importante lembrar que "a relação entre arte e tecnologia sempre esteve presente historicamente, elas sempre foram palavras irmãs" (GOIFMAN, 2007). Essa relação não começou com o surgimento dos computadores. Em 1965,

Em um primeiro momento, as câmeras portáteis ainda filmavam em película.

com o advento do Portapack da Sony (o primeiro equipamento portátil de vídeo), possibilita-se aos artistas, pela primeira vez, aquilo que antes só era possível por meio dos grandes estúdios de TV: captar e poder ver ao mesmo tempo as imagens em movimento, ocorrendo de forma inédita na experiência artística a simultaneidade e o imediatismo de tempo entre produção e recepção de mensagem. (MELLO, 2008, p. 73)

O imediatismo ao qual Christine Mello se refere não fez surgir apenas "uma espécie de televisão privada" (MACHADO, 1990, p. 67), mas também um cinema autônomo, pois as câmeras de vídeo utilizam fita magnética, dispensando processos fotoquímicos de revelação. Nessas situações,

sempre que uma nova tecnologia se apresenta ela acaba gerando também, por um lado, um certo deslumbre e, por outro, o preconceito por parte da 'elite artística estabelecida'.(GOIFMAN, 2007)

filmes fantásticos, como La Manoir du Diable (1896) e Voyage à travers l'impossible (1904). 
No Brasil, os desdobramentos da chegada do vídeo não foram diferentes das afirmações do cineasta Kiko Goifman, com um agravante: o alto custo dos equipamentos fez com que eles ficassem restritos a um número diminuto de artistas ${ }^{7}$.

Nesse cenário, a produção de documentários brasileiros nos anos 1960 e 1970 sofreu pouco impacto com a tecnologia videográfica. E, para a "elite artística estabelecida" do cinema nacional, não era possível "filmar" com uma câmera de vídeo, o ato era um privilégio das câmeras com película. Consequentemente, não se podia "fazer cinema" com o vídeo, apenas videoarte. Tal postura contribuiu para aumentar o abismo imaginário entre o cinema e as artes visuais.

O contexto do documentário brasileiro começou a ser alterado a partir dos anos 1980, com o surgimento de coletivos como a TVDO e o Olhar Eletrônico. Ainda assim, a popularização do documentário acontecia de forma discreta, e sua semelhança com as reportagens televisivas continuava grande.

No início dos anos 1990, o cenário do cinema no Brasil era o pior de sua história. O governo Collor (1990-1992) e suas desastrosas medidas econômicas extinguiram todas as formas de financiamento a filmes brasileiros, tornando a produção cinematográfica nacional praticamente inexistente durante esses anos. Após o impeachment, a produção de filmes voltou a ser fomentada, principalmente através de mecanismos de isenção fiscal. As obras desse período ficaram conhecidas como Cinema da Retomada, uma política de mercado e não um movimento cinematográfico, o qual nasce "quando indivíduos que compartilham o mesmo ponto de vista ou a mesma ótica juntam-se formal ou informalmente". (NICHOLLS, 2016, p. 50). Quase todos os filmes desse momento foram produzidos pelas Organizações Globo. Não por coincidência, seus elencos eram praticamente os mesmos das novelas da emissora. Documentários não estavam na ordem do dia.

Na virada do milênio, as coisas mudaram para o documentário. Em 1998, Kiko Goifman lançou o Cd-rom Valetes em Slow Motion. Um trabalho híbrido, formando um documentário não-linear. Premiado mundialmente, a obra anunciava que o documentário e a tecnologia digital seriam grandes parceiros.

Logo no início dos anos 2000, o formato DV (Digital Video) chegou ao mercado brasileiro. Câmeras compactas como as Sony PD-150 e VX-1000 ofereciam uma qualidade de som e imagem compatível com modelos topo de linha. Computadores Apple Macintosh começaram a substituir ilhas de edição que ocupavam salas inteiras. A proposição/conceito de Glauber Rocha finalmente estava tornando-se realidade no Brasil.

Uma nova maneira de se fazer audiovisual surgiu com as tecnologias que "propiciaram não só um barateamento radical de produção como também a realização mais simples de filmes íntimos, com equipes reduzidas" (GOIFMAN, 2007). Essa forma mais simples - e não simplista - ofereceu um novo modo de acesso ao outro. Amir Labaki (2006, p. 10), diretor do festival É Tudo Verdade, dedicado ao cinema

\footnotetext{
7 Os livros "Made in Brasil: três décadas do vídeo brasileiro" e "Extremidades do Vídeo", de Arlindo Machado e Christine Mello, respectivamente, discorrem sobre esse período.
} 
documentário, afirma que "o digital no Brasil ampliou a definição de documentarista".

O Youtube, lançado em 2005, revolucionou os métodos de distrubuição do audiovisual. $O$ cinema documentário recebeu com entusiasmo as plataformas online de vídeo, pois elas trouxeram uma nova

possibilidade de rompimento com o tradicional problema que temos de distribuição e divulgação. Se na produção já temos uma novidade que vem do barateamento e as possibilidades de experimentação, a questão da difusão do cinema pode, num futuro próximo, passar pela lógica contemporânea das redes. (GOIFMAN, 2007)

O futuro próximo ao qual Goifman se refere chegou há mais de uma década, com o fortalecimentos de espaços virtuais como

Youtube e Facebook, onde proliferam imitações de documentários, quase documentários, semidocumentários, falsos-documentários e documentários genuínos, que adotam formas novas e abordam temas novos. (NICHOLLS, 2016, p. 26)

Esse é o nosso momento atual, onde são feitos documentários que "tratam de pessoas reais que não desempenham papéis [...] elas "representam" ou apresentam a si mesmas" (Ibid, 2016, p. 31). Não que isso não acontecesse antes mas, agora, as histórias de pessoas reais são contatadas por pessoas também reais. Os indivíduos podem contar suas próprias histórias, não é mais necessário que isso seja feito pelos "donos do cinema" que criam o seu tratamento criativo para a realidade do outro. Foi com intuito de compartilhar ferramentas para esse processo que surgiu a oficina Documentários em Vídeo Digital.

\section{A oficina Documentários em Vídeo Digital}

Em 2018, a oficina Documentários em Vídeo Digital foi incorporada ao programas Pontos MIS e Oficinas Culturais da POIESIS. O Pontos MIS é uma plataforma de difusão audiovisual que promove a formação de público e a circulação de obras de cinema. Uma parceria entre o Museu da Imagem e do Som (MIS) e 120 cidades. A POIESIS é uma Organização Social que atua junto ao Governo do Estado de São Paulo. Seu objetivo é o estímulo à criação artística e intelectual. São programas cuja principal meta é a descentralização do acesso à cultura.

A duração das oficinas é variável: nos Pontos MIS elas duram quatro horas; nas Oficinas Culturais, podem ter de quatro a dezeseis. Apesar da curta duração, a ideia é que os participantes possam "parar para pensar, parar para olhar, parar para escutar, pensar mais devagar, olhar mais devagar, e escutar mais devagar". (LARROSA, 2002, p. 24).

A primeira atividade aconteceu em Alumínio, em junho de 2018. Semanas depois, foi a vez de São Pedro do Turvo, Pirajú, Fartura, Bernardino de Campos e Itaí. 


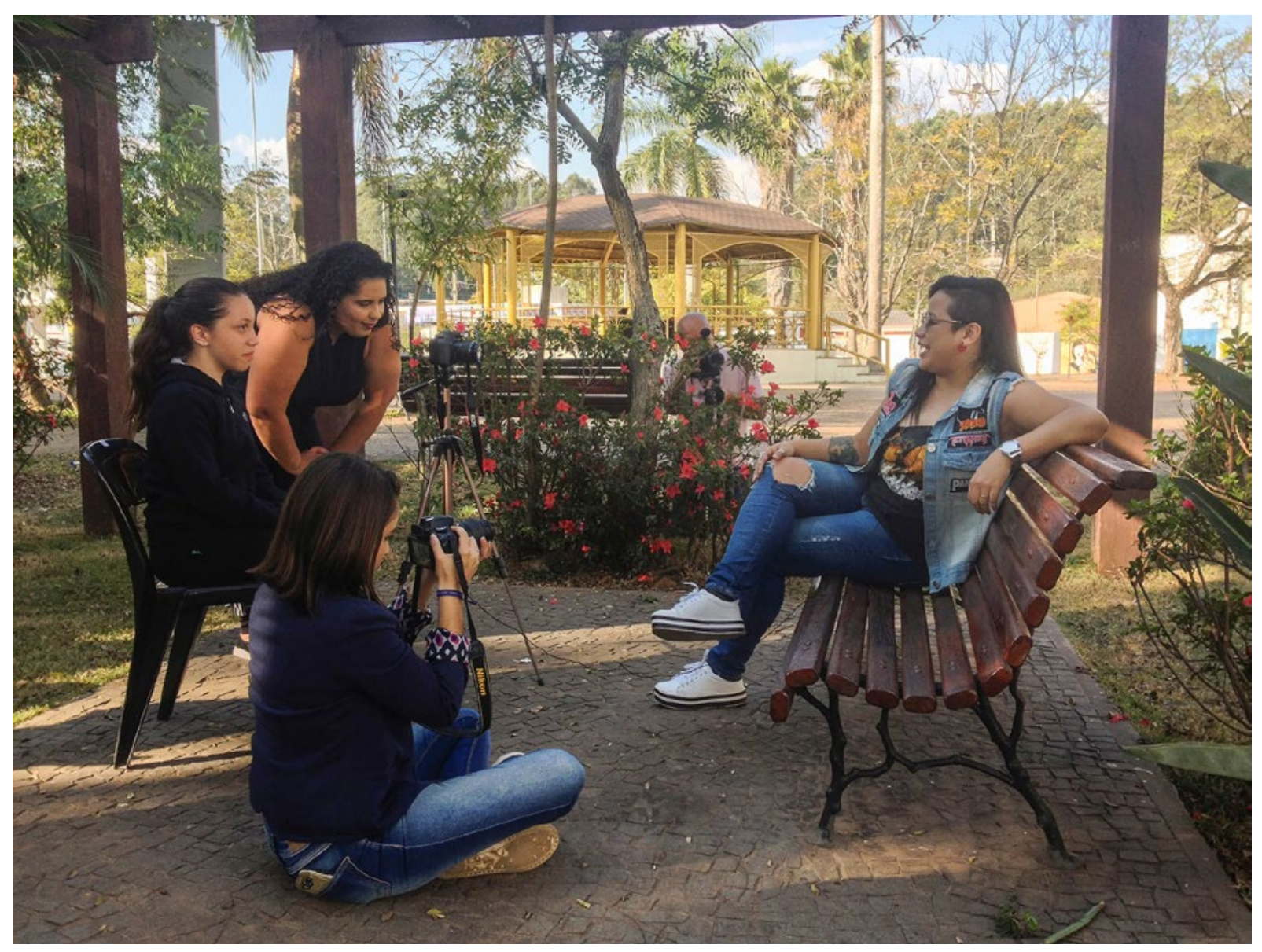

Fig. 01. Documentários em Vídeo Digital. Alumínio, 2018. Fotografia do próprio autor.

Nas semanas seguintes, fiz uma análise sobre como as primeiras atividades tinham se desenrolado e percebi que, em nenhuma das cidades, o conteúdo preparado havia sido compartilhado da mesma forma. Cada lugar demonstrou ter a sua especificidade. Compreendi que não poderia usar um roteiro fechado, pois, "uma vez fossilizado, o método é uma figura linear, retilína" (Ibid, 2003, p. 112). Imaginei as oficinas como um grande bate-papo, e não uma aula tradicional, onde se desenvolve uma

lógica de destruição generalizada da experiência e os aparatos educacionais também funcionam cada vez mais no sentido de tornar impossível que alguma coisa nos aconteça. (Ibid, 2002, p. 23)

Passei a me interessar por ser um mediador, ou melhor, um provocador, criando um ambiente onde "a imagem do "eu" é suavizada". (IRWIN, 2004, p. 31).

A atividade passou a iniciar-se com uma breve apresentação dos participantes. Essa prática ajudou a definir qual rumo a oficina tomaria. Em Documentários em Vídeo Digital, teoria e prática não são vistas como coisas dicotômicas, "mas sim dialéticas, e, se fosse preciso constituir preferência entre as duas, seria para a prática, e não para a teoria". (lbid, 2004, p. 29). 


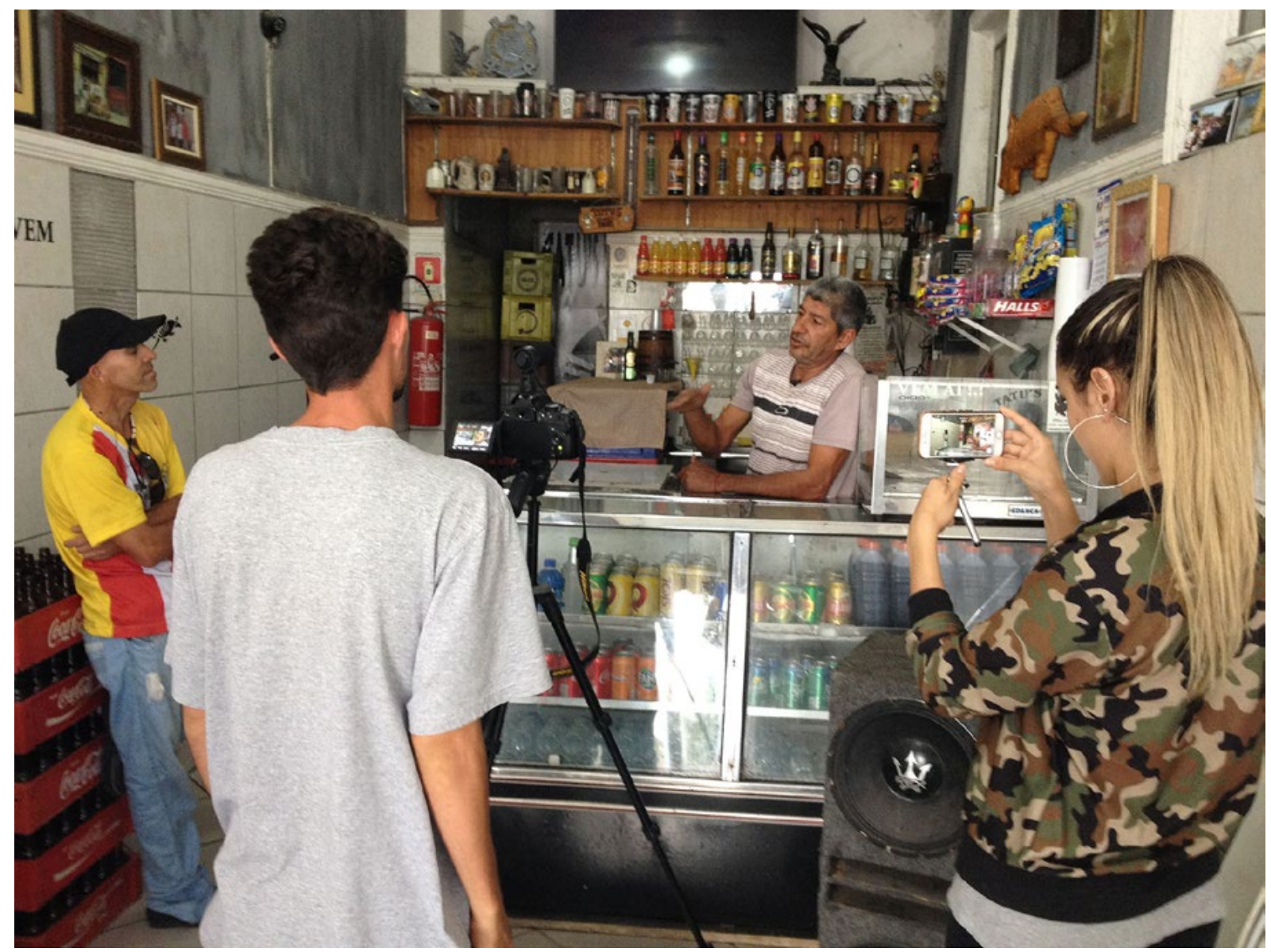

Fig. 02. Documentários em Video Digital. Potim, 2018. Fotografia do próprio autor.

Depois do primeiro ano de oficinas, percebi como o público foi diverso, não sendo possível traçar um perfil padrão: desde adolescentes na faixa dos 14 anos até adultos com mais de 70; com ocupações das mais variadas.

Houve uma ocasião em que, no mesmo dia, ministrei a atividade em Piacatú (5.000 habitantes) e Presidente Prudente (230 mil habitantes). Nessa situação, a flexibilidade para readaptar do conteúdo foi fundamental.

Como "o novo conhecimento afeta o conhecimento existente" (Ibid, 2004, p. 37), para o segundo ano da prática reformulei parte do material. Por exemplo, nos exercícios de captação de áudio, as gravações passaram a ser feitas simulando entrevistas.

Em janeiro de 2019, a oficina fez parte da $22^{a}$ Mostra de Cinema de Tiradentes$\mathrm{MG}^{8}$. Nessa oportunidade, a atividade teve uma dinâmica diferente. Devido à grande procura, a turma teve 40 pessoas. Como o público era familiarizado com o cinema, não foi necessário o enfoque em alguns assuntos introdutórios mas, ao mesmo tempo, as atividades práticas se tornaram mais limitadas em função do número de participantes. Mesmo assim, conseguimos desenvolver uma série de entrevistas entre eles, exercícios de captação de som e princípios básicos da edição. Ao final de três dias, o resultado foi satisfatório e a oficina bem avaliada pelo público.

8 O making-of da atividade está disponível em: <https://youtu.be/q3q8ltoYmvA>. 


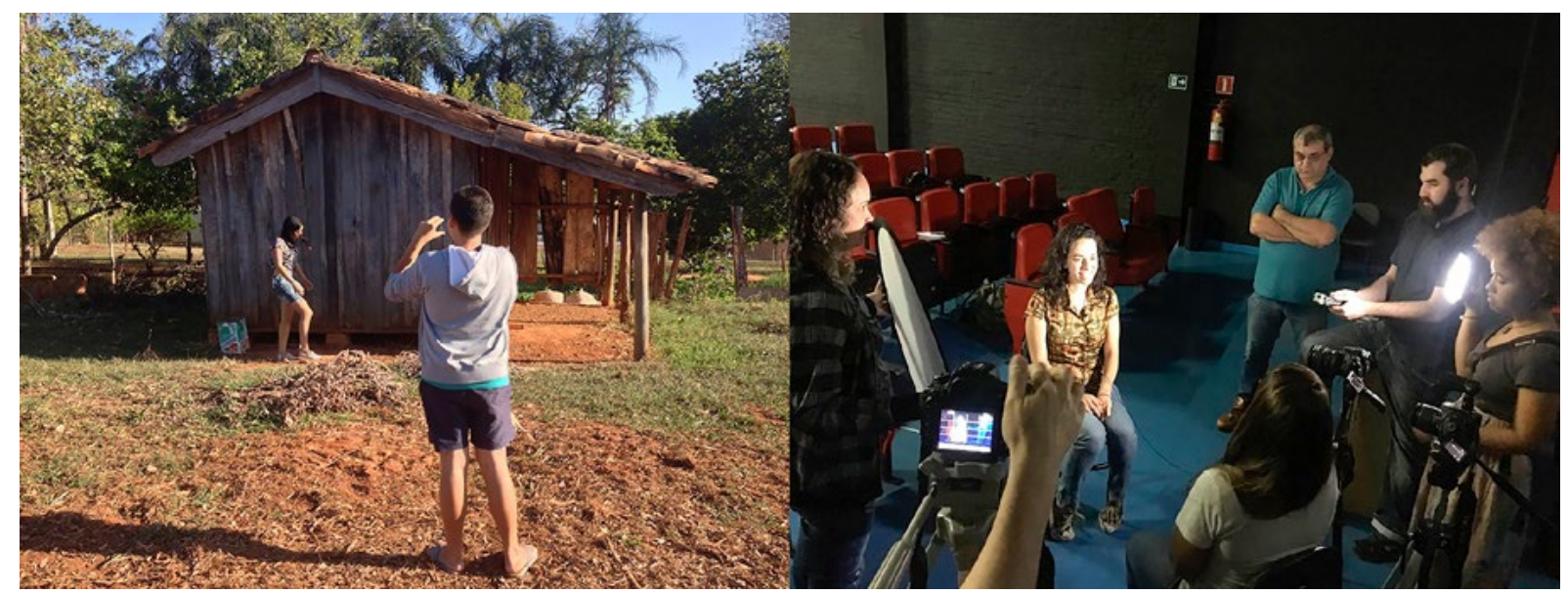

Fig. 03. Documentários em Video Digital em Piacatú e Presidente Prudente, 2018. Fotografia do próprio autor.

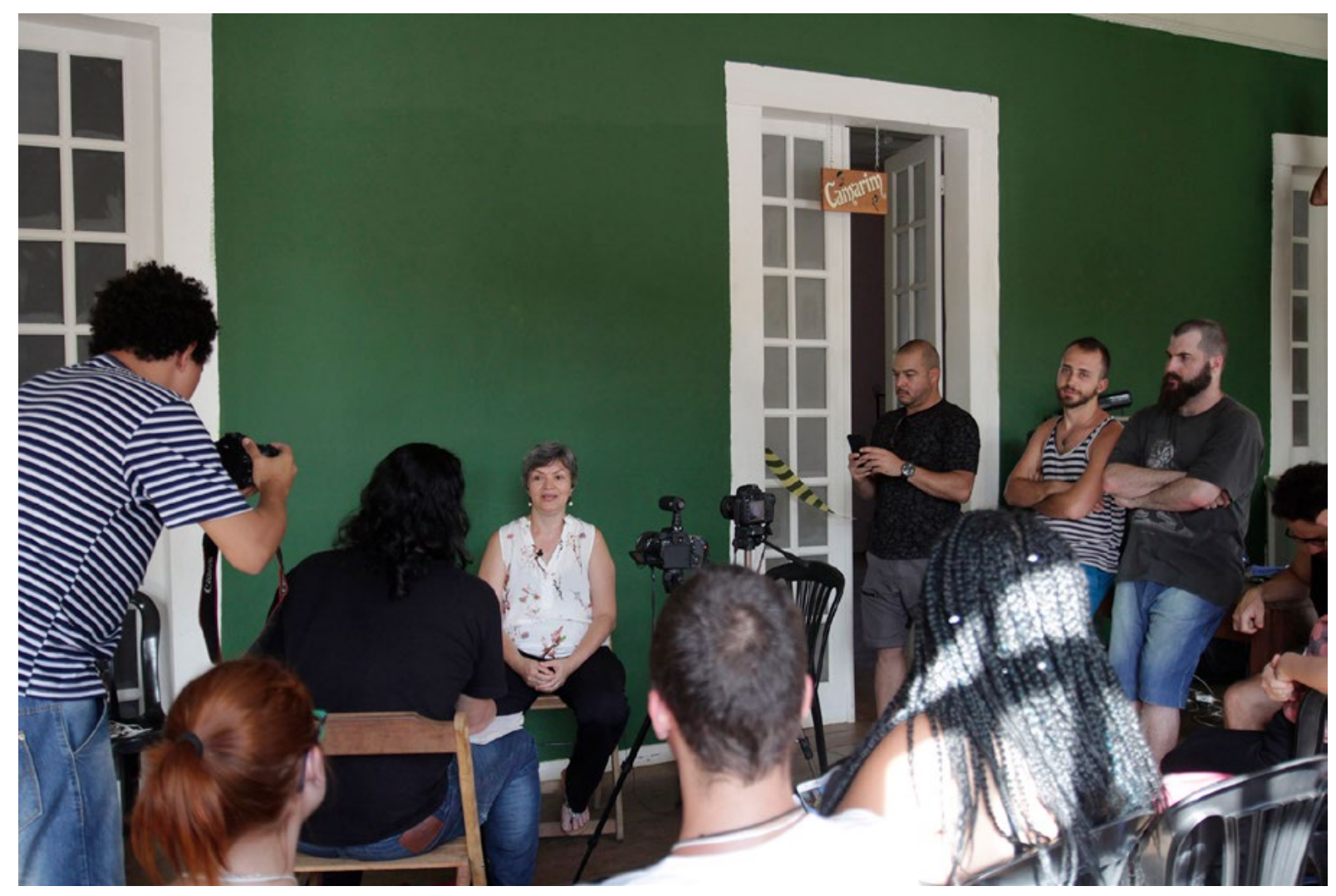

Fig. 04. Documentários em Vídeo Digital. Tiradentes-MG, 2019. Fotografia: Iris Mendes.

Foi comum, ao decorrer do ano, as oficinas acontecerem em blocos de cinco cidades ao longo de cinco dias. Isso só foi possível graças à uma equipe de produção competente, que fornece todo o suporte aos oficineiros que estão na estrada. Para facilitar o deslocamento, optei por um conjunto básico de equipamentos que coubessem em uma mala pequena. Um kit constituído por uma câmera DSLR Canon 70D com lente 17-50mm, um microfone direcional portátil Nikon ME-1, um microfone de lapela Kanko, um gravador Tascam DR-05, um iluminador de LED, um rebatedor, um tripé e diversos adaptadores. Esse equipamento proporciona a versatilidade que 
o cinema documentário requer. Os microfones mencionados podem ser utilizados com telefones celulares, proporcionando a gravação de áudio e vídeo sincronizados em um dispositivo de uso diário.

Um dos principais exercícios propostos é a realização de entrevistas entre os participantes. Embora seja abordado que um documentário não necessariamente precise ter entrevistas, em algum momento da criação fílmica haverá um encontro com outras pessoas; seja na pesquisa, pré-produção ou mesmo nos bastidores da filmagem. É por isso que, "de todas as artes, o cinema é incontestavelmente a menos afastada da realidade social" (AUMONT, 2004, p. 09). A intenção é que essa prática seja como uma conversa entre duas ou mais pessoas, e não como uma típica entrevista jornalística, onde o reporter detém o poder de fala, muitas vezes, representado pelo uso do microfone. O próprios participantes escolhem as pautas e os locais de gravação. Ao final, é mostrado a eles como se faz a preparação do material para a edição.

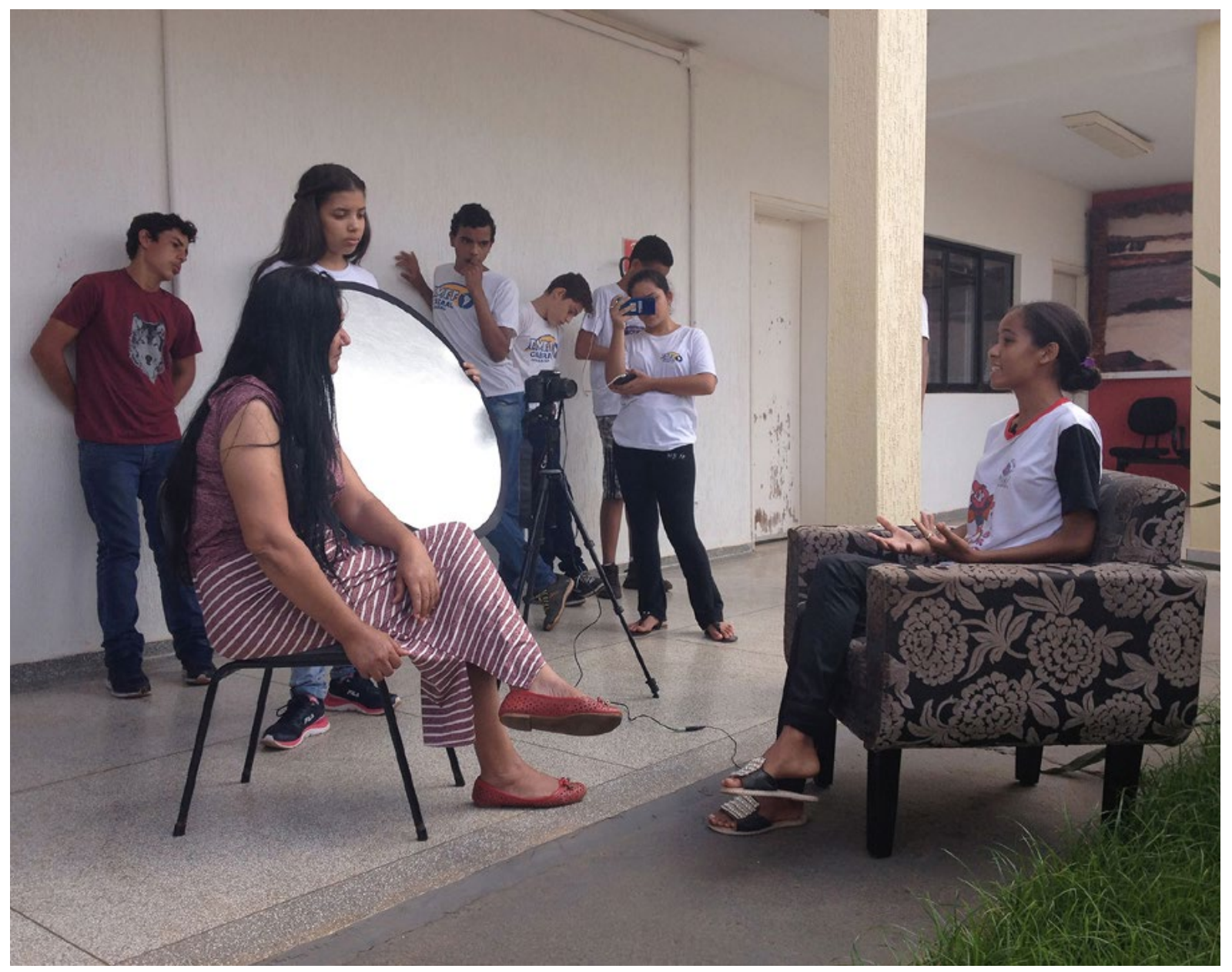

Fig. 05. Documentários em Vídeo Digital. Ouroeste, 2019. Fotografia do próprio autor.

Em cidades onde a oficina teve uma carga horária maior, foi possível a realização de documentários de curta duração (entre um e quatro minutos). Uma criação coletiva, desde a elaboração do roteiro até a captação e montagem. Os mini-documentários têm como personagens participantes da atidade. É o caso dos trabalhos produzidos 
em Várzea Paulista, Vargem Grande do Sul, Itapira, Engenheiro Coelho, Santa Gertrudes e Santana de Parnaíba?.

Em praticamente todas as cidades foram gravadas entrevistas. Ao me deparar com a riqueza desse material surgiu a ideia de orgarnizá-lo em um único filme, assim se iniciou o processo de criação de Fora da Capital. Se toda a oficina se baseia no cinema documentário, por que não produzir um a partir dela?

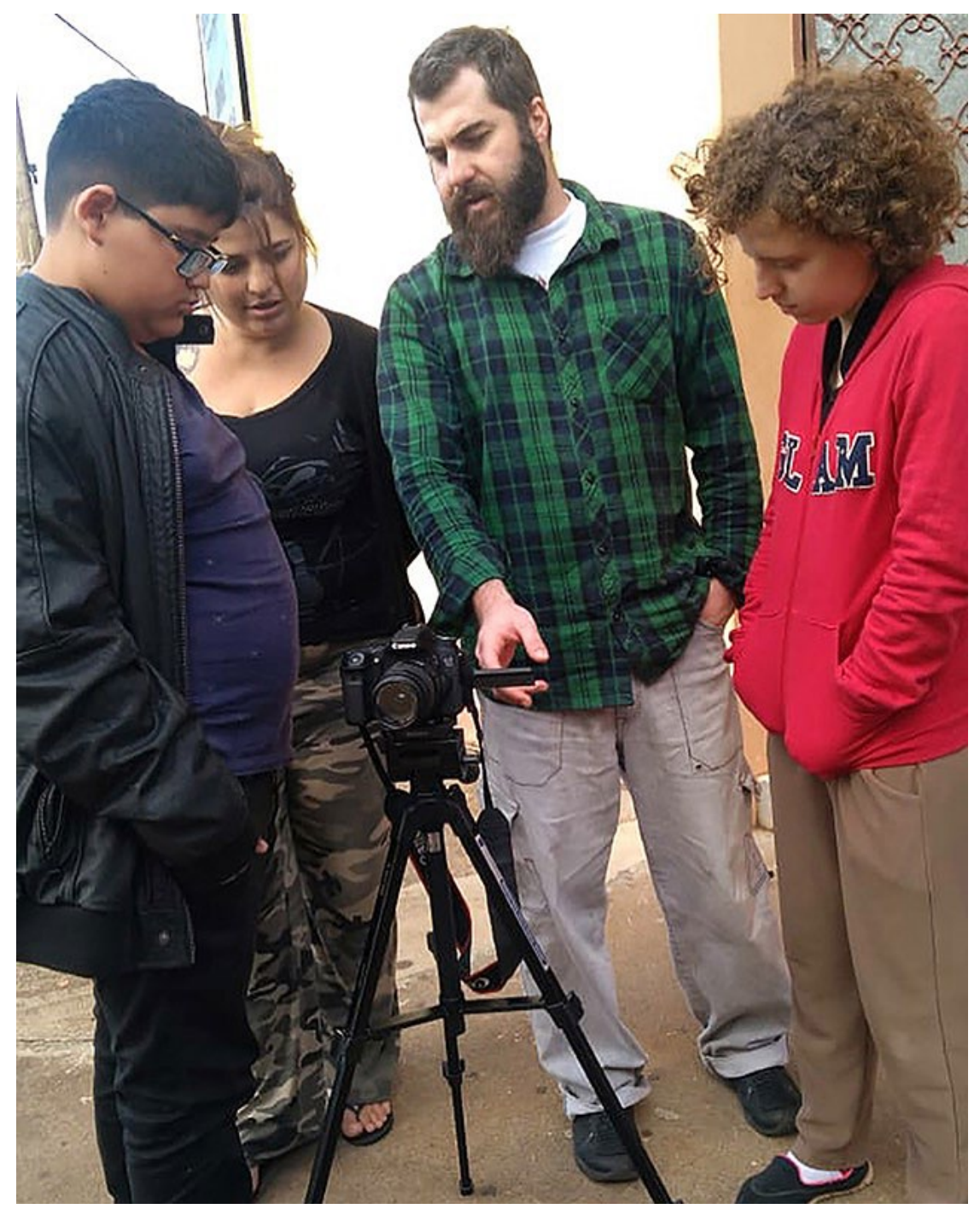

Fig. 06. Documentários em Video Digital. Bernardino de Campos, 2018. Fotografia: Rosana Mimura.

\section{Fora da Capital}

O conteúdo gravado ao longo dos dois anos de atividade era formado por mais de 60 entrevistas e horas de imagens de cobertura. Um ponto importante antes de iniciar a edição e montagem, foi entender que o objetivo não era fazer um filme

\footnotetext{
9 Trabalhos disponíveis em: <www.youtube.com/playlist?list=PLFztEVmsZ70V6j3Rf5Y2iprplsjBNYSO>.
} 
sobre as oficinas, como um making of, mas sim um trabalho com os participantes. Tinha em mente questões como: "quando os documentários contam uma história, de quem é a história? Do cineasta ou das pessoas que ele filma?" (NICHOLLS, 2016, p. 34). Minha função não seria de diretor, mas sim de organizador.

Ao fazer a decupagem das entrevistas foi possível notar a diversidade do material gravado e perceber que

os sotaques, as maneiras de falar, a elocução oral, o ritmo são tantas características pelas quais linguagem falada em um filme se torna fator de poesia. (AUMONT, 2004, p. 94)

A multiplicidade de imagens também estava no aspecto técnico, uma vez que foram usados diferentes tipos de câmeras e as gravações ocorreram locações como teatros, casas de cultura, bibliotecas, museus, escolas, à beira de uma ferrovia, um prédio abandonado ou o boteco da praça central.

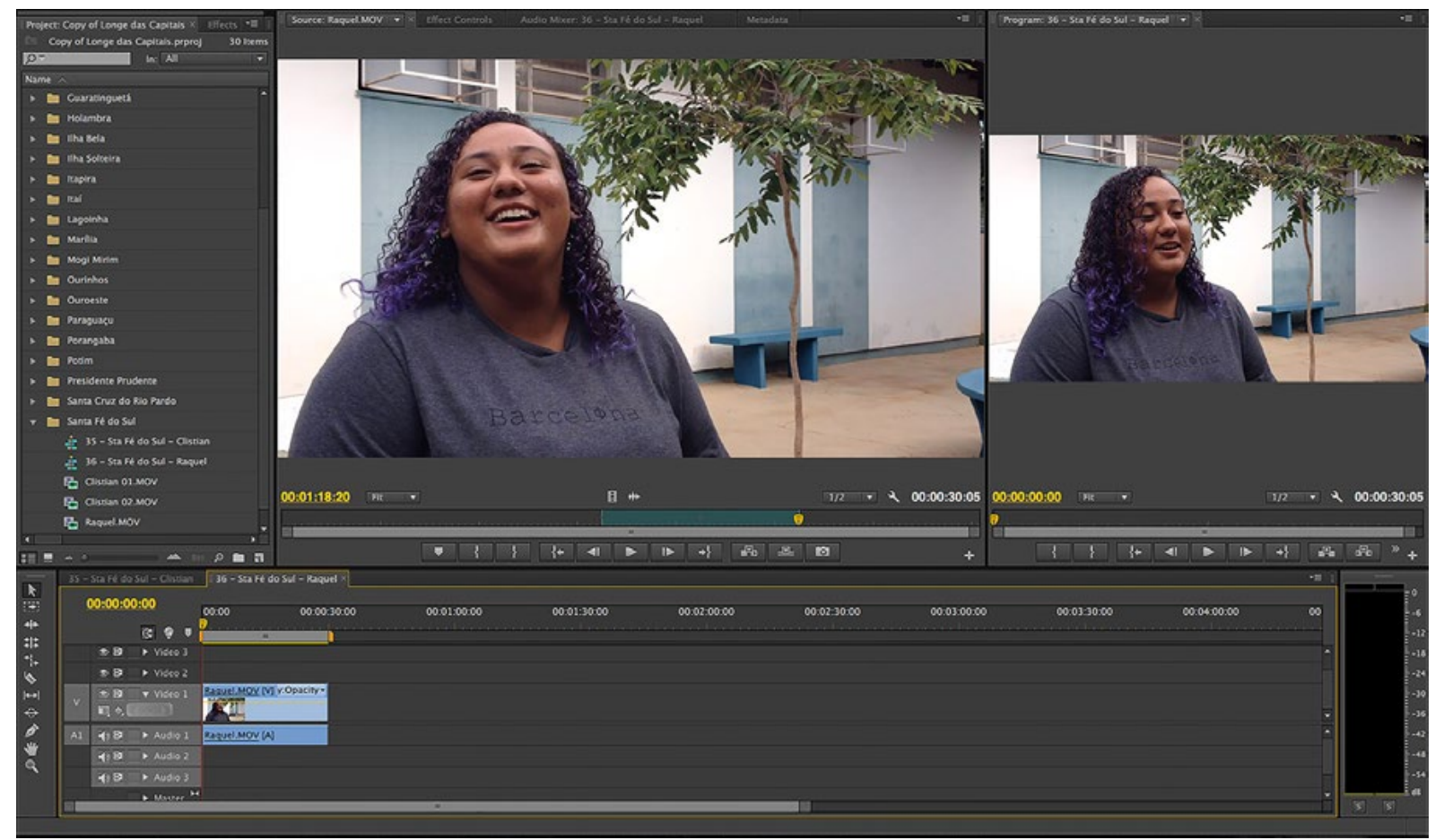

Fig. 07. Captura de tela da edição de Fora da Capital, 2020.

Durante as gravações, os participantes foram orientados a usarem enquadramentos que privilegiassem os rostos dos entrevistados, lembrando que

o cinema releva algo da interioridade dos sujeitos filmados [...] filmar um ser humano e especialmente o seu rosto é aprender algo a seu respeito. (Ibid, 2004, p. 70)

Para a montagem, procurei definir o que não queria:

- Evitar que o filme seguisse a lógica de uma viagem linar: saindo do Litoral Norte, passando pelo Vale do Paraíba, região metropolitana de São Paulo e, depois, 
rumo ao interior, como um "bandeirante pós-moderno".

- Não blocar os personagens por idade.

- Não separar os personagens por profissões. Isso poderia sugerir alguma hierarquia.

- Não agrupar as falas de maneira que uma sirva apenas para reforçar o que foi dito na anterior.

Optei por um filme que retratasse encontros. Mas não o tipo de encontro proposto por cineastas como Eduardo Coutinho ou Michael Moore, onde eles se tornam personagens e performam para a câmera, muitas vezes tomando o protagonismo para si mesmos; mas sim um tipo de encontro entre os personagens, como se eles conversassem entre si. Como se a estudante Daniele, de Tatuí, pudesse se contrar com o também estudante Felipe, de Vargem Grande do Sul, mesmo os dois vivendo a 270 quilômetros de distância.

Para transparecer a ideia do deslocamento pelo estado, é informado o primeiro nome de cada personagem e a cidade onde vive. Dentro desse conceito, foram inseridas sequências de imagens de estrada ao longo da narrativa.

O processo de montagem foi feito entre os meses de fevereiro e maio de 2020, e o filme se transformou em um longa-metragem com mais de 70 minutos. Ao todo, participam 43 pessoas de 35 cidades diferentes.

Fora da Capital ainda não tem uma previsão para sua primeira exibição pública. O objetivo é que o filme possa integrar o circuíto de festivais brasileiros e também seja exibido nas cidades onde foi filmado. Sua distribuição será a próxima etapa de trabalho.

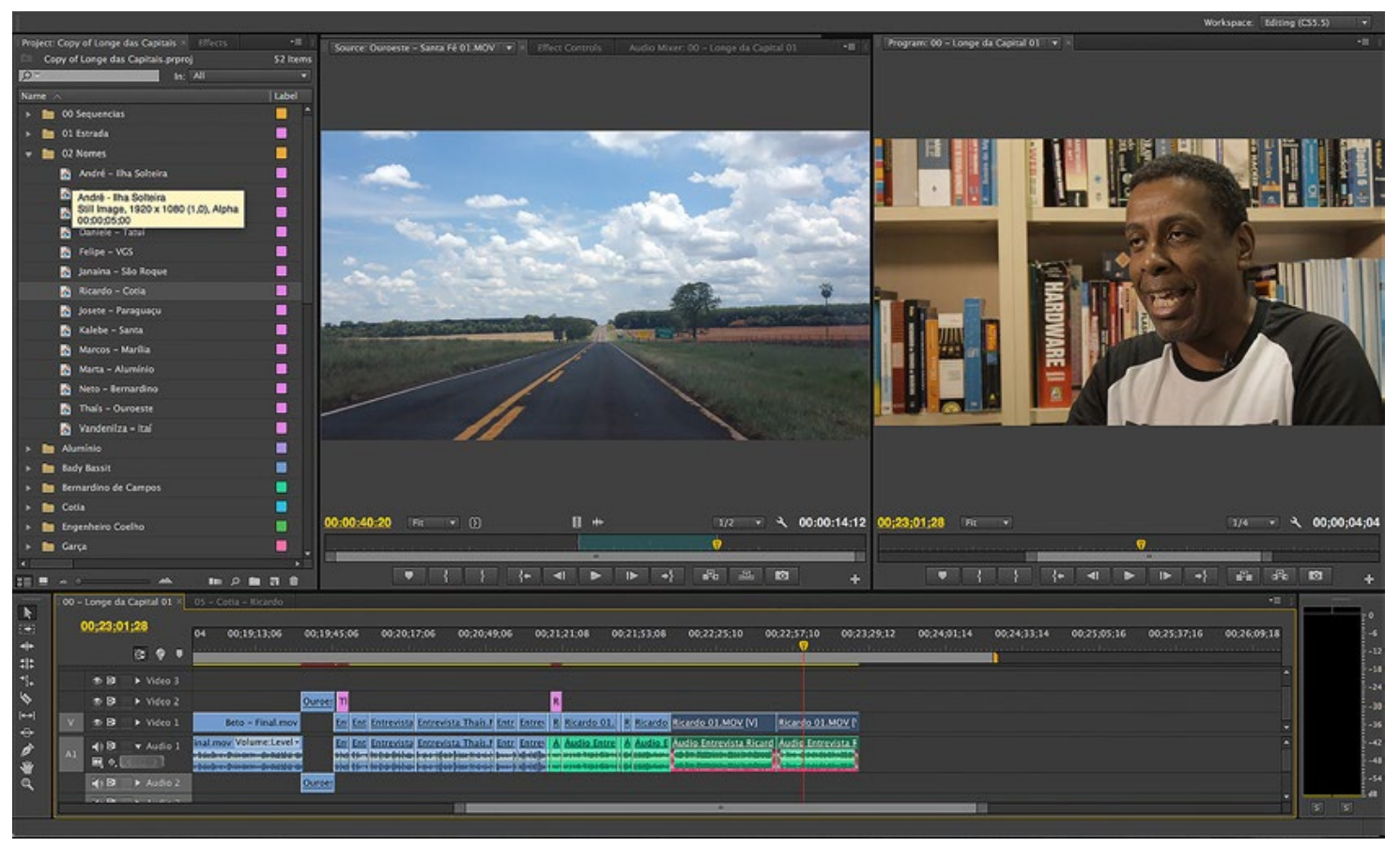

Fig. 08. Captura de tela da edição de Fora da Capital, 2020. 


\section{Conclusão}

Nos últimos anos, o documentário voltou a ocupar um lugar de destaque nas discussões cinematográficas. No Brasil, foi possível notar esse fenômeno através de filmes como O Processo (2018), de Maria Augusta Ramos; Democracia em Vertigem (2019), de Petra Costa e Bixa Travesty (2018), de Cláudia Priscilla e Kiko Goifman. Infelizmente, boa parte dos debates acerca desses três multi-premiados filmes foi feita pelo viés polarizado da política brasileira, deixando passar a oportunidade de se discutir a linguagem documental.

O crescente interesse por documentários - tanto por parte do público quanto por realizadores - tem uma relação com o surgimento de novas plataformas de distrubuição, principalmente via internet. Nos dias atuais, o documentário se expandiu e tornou-se ainda mais amplo, se espalhando por diversas mídias e suportes, ocupando novos tipos de telas. Lives no Facebook e stories no Instagram não deixam de ser formas expandidas de documentários. São diferentes tratamentos criativos da realidade feitos pelos seus autores. No caso dos stories, além de expandidas, essas formas podem ser efêmeras, se configuradas para desaparecerem após 24 horas.

Depois de dois anos bem sucedidos com Documentários em Vídeo Digital, 2020 se iniciou de maneira otimista, com a possibilidade de expansão do número de cidades dos programas e, consequentemente, um alcance maior de participantes. Porém, a pandemia de coranavírus colocou as ações em suspensão e com o futuro incerto. Mesmo durante o período de isolamento social, o filme assumiu o papel levar adiante o pressuposto original da oficina: que os participantes possam contar suas próprias histórias.

Ao me referir a esse trabalho, não gosto de usar palavras como "mapeamento" ou "recorte". O que o filme mostra são pessoas comuns, e um pouco de suas vidas fora da capital.

\section{Referências:}

AUMONT, Jacques. A teoria dos cineastas. Campinas, Papirus: 2004.

BAMBOZZI, Lucas. O vídeo expandido e seus estilhaços. Disponível em: <http://www. lucasbambozzi.net/textos-articles/o-video-explodido-e-seus-estilhacos-pairando-sobrenos>. Acesso em: 15/05/2020.

COSTA, Flavia Cesarino. Primeiro Cinema. In: MASCARELLO, Fernando (org.). História do cinema mundial. Campinas-SP, Papirus Editora: 2006. p.17-52.

GOIFMAN, Kiko. Entrevista concedida a Lucas Gervilla. São Paulo, 17 dez. 2007.

IRWIN, Rita L. A/r/tografy: a metonymic mestissage. In: IRWIN, Rita L e COSSON, Alex (orgs.). $A / r$ tografy: rendering self through arts-based living inquiry. Vancouver, Pacific Educational 


\section{Revista Apotheke}

Press, 2004. p.27-38.

LABAKI, Amir. Introdução ao documentário brasileiro. São Paulo-SP, Francis Editora: 2006.

LARROSA, Jorge. Notas sobre a experiência e o saber da experiência. Revista Brasileira de Educação. Rio de Janeiro-RJ, vol.01, n.19. p.20-28, jan/fev/mar/abr 2002.

LARROSA, Jorge. O ensaio e a escrita acadêmica. Educação \& Realidade. Porto Alegre-RS, vol.28, n.02, p.101-115, jul/dez 2003.

MELLO, Christine. Extremidades do vídeo. São Paulo: Editora Senac São Paulo, 2008.

NICHOLLS, Bill. Introdução ao documentário. Campinas-SP, Papirus Editora: 2016.

RUFFINELLI, Jorge. América Latina em 130 documentários. São Paulo-SP, É Realizações Editora: 2017.

TEIXEIRA, Francisco Elinaldo. Documentário expandido: reinvenções do documentário da contemporaneidade. In: EQUIPE ITAÚ CULTURAL (org.). Sobre fazer documentários. São Paulo-SP: Itaú Cultural, 2007. p.40-45.

RAMOS, Fernão Pessoa. Introdução à $6^{\text {a }}$ edição brasileira. In: NICHOLLS, Bill. Introdução ao documentário. Campinas-SP, Papirus Editora: 2016. p.11-15.

Recebido em 04 de maio de 2020. Aprovado em 02 de junho de 2020. 